\title{
Clinical and laboratory parameters which affect soluble interleukin-2 receptor levels in the serum and synovial fluids of patients with rheumatoid arthritis
}

Tomoko Matsumoto, Katsuro Iwasaki

\begin{abstract}
Objective-To investigate whether soluble interleukin-2 receptor ( $\mathbf{l}$ IL-2R) could be a useful marker of disease activity in rheumatoid arthritis (RA); sIL-2R levels in serum and in synovial fluid were determined by enzyme-linked immunosorbent assay.

Methods-Sixty five serum and 27 synovial fluid samples were obtained from patients with RA. Twenty five serum and 28 synovial fluid samples from patients with osteoarthritis (OA) were used as controls. Furthermore, 10 synovial fluid samples from healthy volunteers were also examined. Variable laboratory and clinical data were compared with serum sIL-2R levels, in 26 patients with $R A$ and serial samples from some patients were examined.
\end{abstract}

Results-Concentrations of sIL-2R in serum (median 81, range 40-350 pM) and synovial fluid (median 125, range 52-460 pM) from patients with $R A$ were significantly higher than in serum (median 45, range $13-100 \mathrm{pM}$ ) and synovial fluid (median 37, range 15-140 pM) from patients with $O A$, and healthy control synovial fluid (median $2 \cdot 5$, range 0-10 pM). Serum sIL-2R levels correlated strongly with serum levels of C-reactive protein $(p=0.0001)$, and a significant correlation with erythrocyte sedimentation rate $(E S R)(p=0 \cdot 048)$, IgG levels $(p=0.028)$, IgA levels $(p=0.044)$ and Lansbury Index $(p=0.037)$ was observed. However, serum sIL-2R levels showed no significant correlation with rheumatic factor, IgM or $T$ cell subsets.

Conclusion-These findings indicate that sIL-2R levels in patients with $R A$ reflect disease activity.

(Ann Rheum Dis 1993; 52: 876-880)

Activated T cells, ${ }^{1} \mathrm{~B}$ cells, ${ }^{2-4}$ natural killer cells ${ }^{5}$ and macrophages ${ }^{67}$ express interleukin-2 receptors (IL-2R) on their surface. The IL-2R are composed of $\alpha, \beta, \gamma$ heterotrimers. The 55 kd $\alpha$ chain $^{8} 9$ binds IL-2 with low affinity $\left(\mathrm{Kd}=10^{-8} \mathrm{M}\right)$, the $75 \mathrm{kd} \beta$ chain binds IL-2 with intermediate affinity $\left(\mathrm{Kd}=10^{-9} \mathrm{M}\right) .{ }^{10}$ The $\gamma$ chain is necessary for the formation of high and intermediate affinity receptors, and is required for receptor-mediated internalisation of IL-2. ${ }^{1011}$ Following lymphocyte activation, the $\alpha$ polypeptide chain, in addition to being expressed on the cell surface, is released in soluble form, ${ }^{12}$ which is $8-10 \mathrm{kd}$ less than their parent cell surface membrane receptor. Thus by detection of soluble IL-2 receptors (sIL-2R) in serum, lymphocyte activation can be assessed.

High concentrations of serum sIL-2R have been reported in patients with various autoimmune diseases ${ }^{13} 14$ including rheumatoid arthritis (RA), ${ }^{15}{ }^{16} \mathrm{~T}$ cell leukaemia ${ }^{17}$ and granulomatous disease.$^{18}$ Correlations between sIL-2R levels and disease activity have also been described in these diseases. ${ }^{1316} 1920$ However, controversy exists on whether elevated levels of sIL-2R in the serum of RA patients reflects disease activity, ${ }^{15}$ as several studies on sIL-2R regulation have demonstrated. ${ }^{21} 22$

In this study we measured the sIL-2R levels in serum and synovial fluid of patients with RA, and determined whether they correlated with clinical and laboratory parameters of disease activity.

\section{Materials and methods}

\section{PATIENTS}

Serum was obtained from 65 patients (14 men and 51 women) with $\mathrm{RA}$, as defined by the criteria of the American Rheumatism Association, ${ }^{23}$ and 23 patients ( 3 men and 20 women) with osteoarthritis (OA), clinically and radiologically diagnosed. Synovial fluid was obtained from 27 patients $(5$ men and 22 women) with RA and 28 patients with $\mathrm{OA}$. Synovial fluid was also collected from 10 healthy volunteers ( 7 men and 3 women).

CLINICAL EVALUATION

A number of clinical variables were examined in each patient. The erythrocyte sedimentation rate (ESR) was determined by the Westergren method. C-reactive protein (CRP) was quantified by a turbidometric method. Rheumatoid factor (RF) was measured by nepherometry and rheumatoid arthritis haemagglutinin (RAHA) was measured by microtitre methods. Serum immunoglobulin levels were determined by nepherometry. 


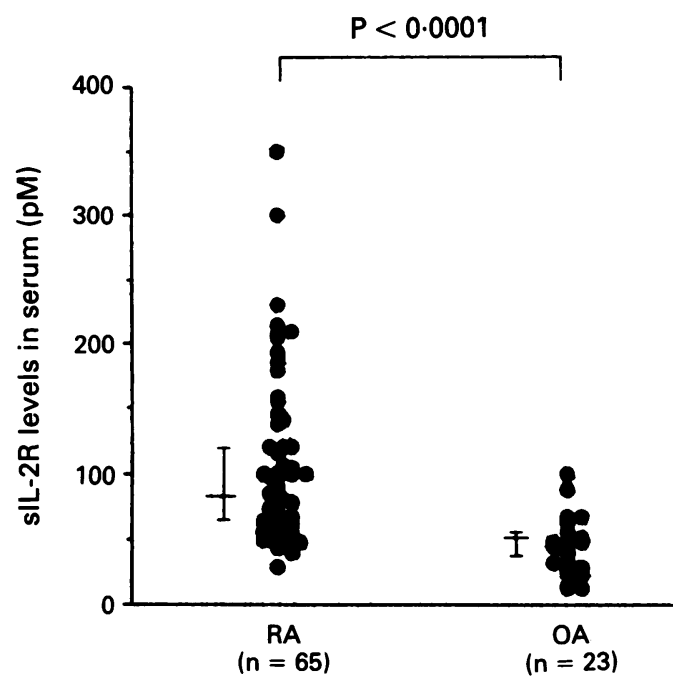

Figure 1 Serum soluble interleukin-2 receptor $($ sIL-2R) levels $(p M)$ in patients with rheumatoid arthritis $(R A)$ and osteoarthritis $(O A)$. Bars represent the median \pm interquartile range.

Fresh heparinised blood was obtained from patients and separated peripheral blood mononuclear cells were stained for 2-colour flow cytometry. The number of cells which expressed the specific surface markers CD4 and CD8 were calculated. The modified Lansbury index ${ }^{24}$ consisted of duration of morning stiffness, number of swelling joints, grip strength and ESR.

SIL-2R ASSAYS

sIL-2R levels in serum and fluid were measured by ELISA. Kits were purchased from Immunotech SA (Marseille, France). The kit contained a coating anti-sIL-2R monoclonal antibody and a second monoclonal antibody conjugated with alkaline phosphatase. Standards of sIL-2R ranging from 0-400 pM were provided.

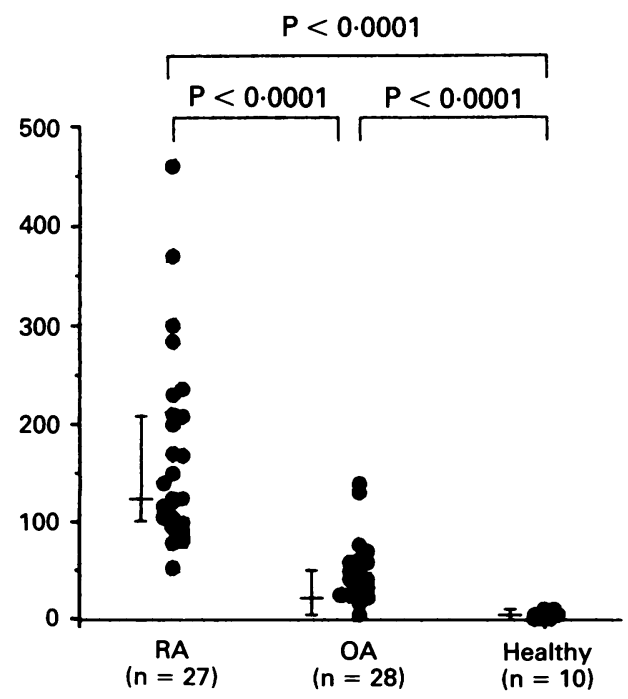

Figure 2 Soluble interleukin-2 receptor (sIL-2R) levels in synovial fluid from patients with rheumatoid arthritis $(R A)$, osteoarthritis $(O A)$ and healthy control subjects. Bars represent median \pm interquartile range.
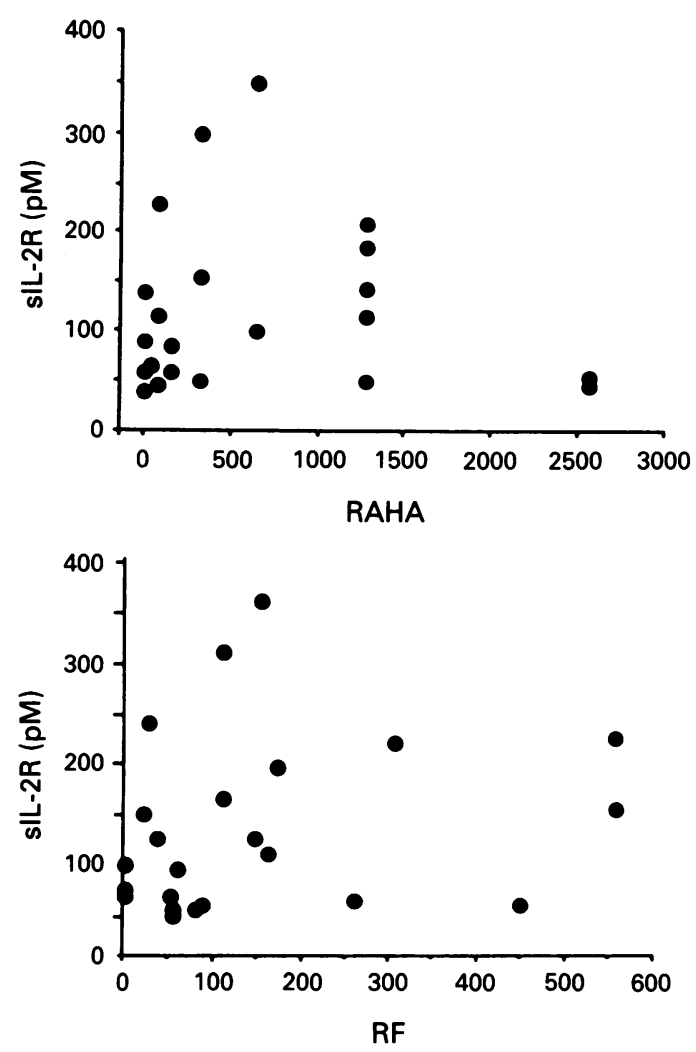

Figure 3 Correlation between serum levels of soluble interleukin-2 receptor (sIL-2R) and rheumatic factor $(R F)$ or rheumatoid arthritis haemagglutinin $(R A H A)$. No statistically significant correlation was found.

STATISTICAL ANALYSIS

All patient data were entered into a computer database and analysed using the Stat View $512+$ program. The Mann-Whitney U test was performed for each set of variables. $P$ values less than or equal to 0.05 were considered
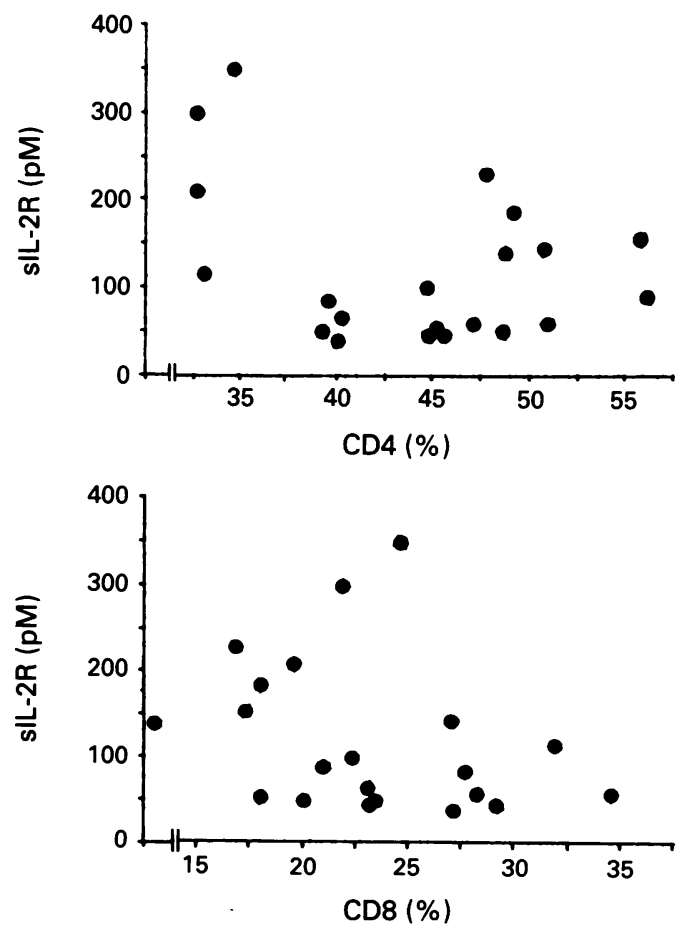

Figure 4 Correlations between serum levels of soluble interleukin-2 receptor (sIL-2R) and CD4 and CD8 T cell subsets in patients with rheumatoid arthritis. No statistically significant correlation was found. 

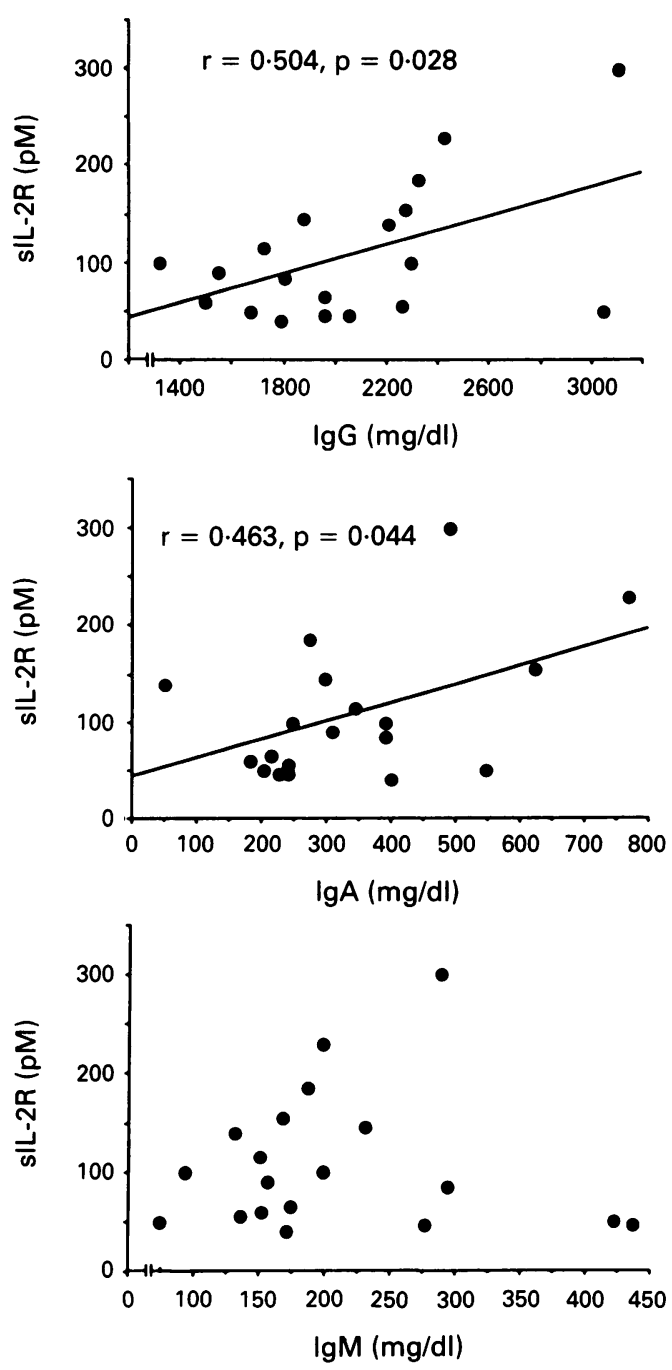

Figure 5 Correlation between serum levels of soluble interleukin-2 receptor (sIL-2R) and immunoglobulin in patients with rheumatoid arthritis. sIL-2R levels correlated positively with $\operatorname{Ig} G(r=0.504, p=0.028)$ and $\operatorname{Ig} A$ $(r=0.463, p=0.044)$, but not with IgM.

significant. Regression analysis and correlations were also performed using the same programme.

\section{Results}

Figure 1 shows that serum sIL-2R levels were considerably elevated in patients with RA

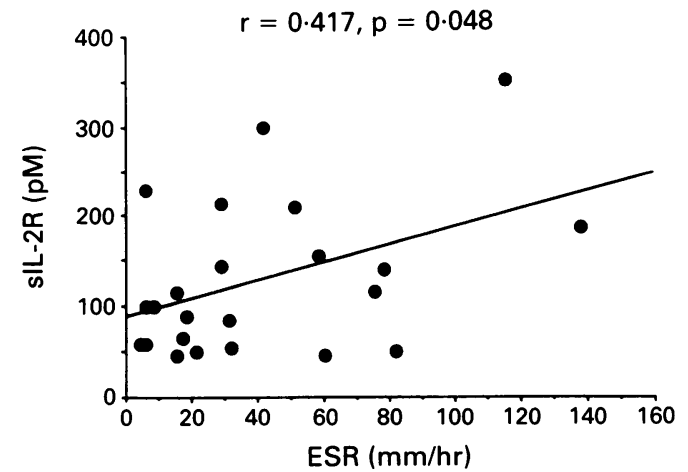

Figure 6 Correlation between serum levels of soluble interleukin-2 receptor (sIL-2R) and erythrocyte sedimentation rate (ESR) in patients with rheumatoid arthritis. A statistically significant correlation was found $(r=0.417, p=0.048)$

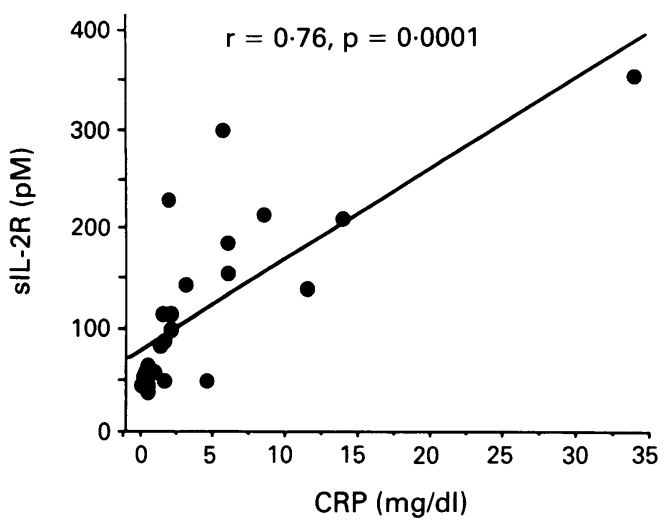

Figure 7 Correlation between serum levels of soluble interleukin-2 receptor (sIL-2R) and $C$-reactive protein (CRP) in patients with rheumatoid arthritis. A statistically significant correlation was found $(r=0.76, p=0.0001)$.

(median 81, range 40-350 pM) compared with the levels in OA patients (median 45 , range $13-100 \mathrm{pM})(\mathrm{p}<0.0001)$.

Figure 2 shows that sIL-2R levels in the synovial fluid of patients with RA (median 125, range 52-460 pM) were significantly higher than in OA patients (median 37, range 15-140 $\mathrm{pM}$ ) and in healthy controls (median $2 \cdot 5$, range $0-10 \mathrm{pM})(\mathrm{p}<0.0001)$.

We also examined relationships between serum sIL-2R levels and clinical and laboratory parameters. There was no correlation between serum sIL-2R and either RF or RAHA (fig 3). The relative percentages of CD4 and CD8 cells in the $T$ cell subsets showed no significant correlations with sIL-2R levels (fig 4). IgG $(\mathrm{r}=0.504, \mathrm{p}=0.027)$ and $\operatorname{IgA}(\mathrm{r}=0.463$, $\mathrm{p}=0.043)$ levels correlated significantly with serum sIL-2R levels, however, IgM did not (fig 5). Although ESR showed only a weak correlation with sIL-2R levels $(r=0.417$, $\mathrm{p}=0.048), \quad \mathrm{CRP}$ correlated strongly $(\mathrm{r}=0.753, \mathrm{p}=0.0001$ ) (fig 6 and 7 ). The Lansbury index also exhibited a positive correlation with serum sIL-2R levels $(r=0.47$, $\mathrm{p}=0.037$ ) (fig 8).

Serum sIL-2R levels and CRP levels were determined from three patients with RA at different times during the course of their treatment. sIL-2R values decreased along with a concomitant decrease in CRP levels (data not shown).

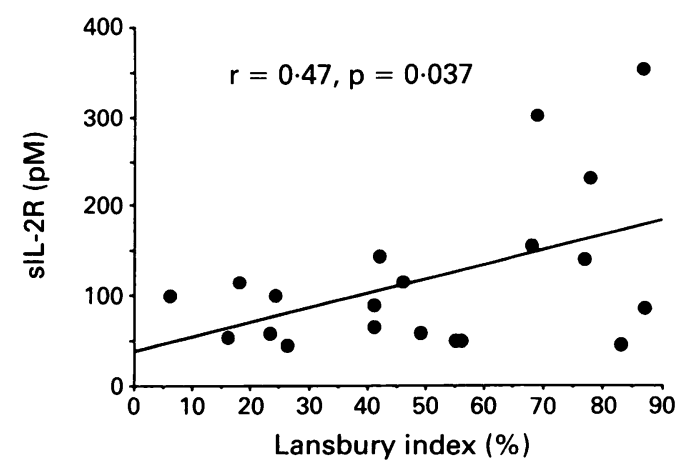

Figure 8 Correlation between serum levels of soluble interleukin-2 receptor (sIL-2R) and modified Lansbury index in patients with rheumatoid arthritis. A statistically significant correlation was found $(r=0.47, p=0.037)$. 


\section{Discussion}

In this study, we confirmed that sIL-2R levels in serum and synovial fluid of patients with $R A$ were significantly elevated compared with patients with OA. Furthermore, in patients with RA, synovial fluid sIL-2R levels (median $125 \mathrm{pM}$ ) were higher than serum sIL-2R levels (median $81 \mathrm{pM})(\mathrm{p}=0.0002)$. In OA patients, however, synovial fluid and serum sIL-2R levels were approximately equivalent. Thus measurement of synovial fluid sIL-2R levels appears to be useful diagnostically for differentiation between arthropathy of RA and OA. These results are compatible with the report by Keystone ${ }^{15}$ suggesting that sIL-2R may be a very sensitive indicator of in situ immune activation. Low levels of sIL-2R in OA synovial fluid indicated significant macrophage infiltration, which may have been the source of sIL-2R.

There have been several reports that serum levels of sIL-2R correlate with disease activity in RA patients. ${ }^{16} 1920$ Campen $^{16}$ described a strong correlation between serum sIL-2R and joint tenderness. Keystone, however, ${ }^{15}$ showed that serum sIL-2R levels did not correlate with disease activity. We examined several laboratory parameters that correlated with serum sIL-2R levels. Our data indicated that CRP showed strongest correlations with serum sIL-2R levels, and following treatment, we observed distinct variations in serum sIL-2R levels associated with concurrent changes in CRP levels (data not shown). In contrast to CRP, ESR showed a weak correlation with serum sIL-2R levels. The ESR is generally considered to be the best available serological marker for monitoring disease activity in patients with RA. However, some exceptions have been demonstrated in RA patients whose disease was in remission. ${ }^{25}{ }^{26}$ When considered in connection with the Lansbury index, it is clear that serum sIL-2R levels in RA patients reflect disease activity.

In this study, immunoglobulins (Ig), IgG and IgA, but not IgM, correlated with sIL-2R levels in serum. This is because activated $T$ cells stimulate B cells to secrete Ig $^{27}{ }^{28}$ but we have no explanation for the lack of correlation between IgM and sIL-2R levels in serum.

Neither serum IgM-RF levels nor RAHA correlated to sIL-2R levels. There is a possibility that circulating RF may nonspecifically bind to the coating IgG monoclonal antibody used in the ELISA. To explore this possibility, several serum samples with hightitre RF were treated by RF absorption, and tested for the presence of sIL-2R and IgM-RF. The level of sIL-2R was found to be comparable with that in paired untreated samples, even when RF had been removed (data not shown). RF and RAHA may not always reflect disease activity, compatible with the above results.

The release of sIL-2R appears to be chiefly a characteristic marker of $T$ lymphocyte activation. In this study, the $T$ cell subsets and sIL-2R levels in serum of RA patients showed no significant correlations. However, we did not examine activation of peripheral blood $\mathrm{T}$ cells, for example, expressing IL-2R or HLA$\mathrm{DR}$, so we cannot discuss here the direct relationship between sIL-2R and $T$ cell subsets. Wagner et $a l^{29}$ demonstrated that $\mathrm{T}$ cells are likely to be the source of elevated serum sIL-2R after administration of human recombinant IL-2. Wood et $a l^{30}$ described the source of the sIL-2R in serum as probably derived from the synovium itself rather than from peripheral blood mononuclear cells. It has been reported that the peripheral blood of patients with RA contains a reduced number of CD8. cells, and that the synovial fluid of these patients contains a significantly different ratio of $T$ cell subsets. ${ }^{31}$ Symons $e t a l^{32}$ showed that synovial fluid levels of sCD4 correlated positively with sIL-2R levels but no correlation with SCD8 levels was observed. Thus $T$ cell subsets in peripheral blood do not reflect the $T$ cell subsets at the site of inflammation, so examination of $\mathrm{T}$ cell subsets in the synovial fluid would provide more accurate information on the relationship with sIL-R levels.

In conclusion, measurement of sIL-2R levels in serum and synovial fluid of patients with $R A$ was useful in assessing disease activity.

1 Robb J R, Munck R A, Smith K A. T cell growth factor receptors; quantitation, specificity, and biological relevance. $\mathcal{F}$ Exp Med 1981; 154: 1455-74.

2 Tsudo $M$, Uchiyama $T$, Uchino $H$. Expression of Tac antigen on activated normal human B cells. $\mathcal{f}$ Exp Med 1984; 160: 612-17.

3 Zubler R H, Lowenthal J W, Erard F, Hashimoto N, Devos R, Macdonald H R. Activated B cells express receptors for, and proliferate in response to, pure interleukin $2 . \%$ Exp Med 1984; 160: 1170-83.

4 Mingari M C, Gerosa F, Carra G, et al. Human interleukin 2 promotes proliferation of activated $B$ cells via surface receptors similar to those activated T cells. Nature 1984 312: 641-3.

5 London L, Perussia B, Trinchieri G. Induction of proliferation in vitro of resting human natural killer cells expression of surface activation antigens. $\mathcal{F}$ Immunol 1985 134: 718-27.

6 Herrmann F, Cannistra S A, Levine H, Griffin J D Expression of interleukin 2 receptors and binding of interleukin 2 by gamma interferon-induced human leukemic and monocytic cells. F Exp Med 1985; 162. leukemic

7 Holter W, Grunow R, Stockinger H, Knapp W. Holter W, Grunow R, Stockinger $\mathbf{H}$, Knapp W.
Recombinant interferon- $\gamma$ induces interleukin 2 receptors on human peripheral blood monocytes. $\mathcal{f}$ Immunol 1986 ; 136: 2171-5.

8 Robb R J, Greene W C, Rusk C M. Low and high affinity cellular receptors for interleukin 2 receptor: Implication for the level of Tac antigen. $f$ Exp Med 1984; 160 $1126-46$

9 Smith K A. The biomolecular structure of the interleukin 2 receptor. Immunol Today 1988; 9: 36-7.

10 Takeshita T, Asao H, Suzuki J, Sugamura K. An associated molecular, p64, with high affinity interleukin 2 receptor. Int Immunol 1990; 2: 477-80.

11 Takeshita $\mathrm{T}$, Asao $\mathrm{H}$, Ohtani $\mathrm{K}$, et al. Cloning of the $\gamma$ chain of the human IL-2 receptor. Science 1992; 257: 379-82.

12 Rubin L A, Kurman C C, Fritiz M E, Biddison W E, Boutin B, Yarchoan R, Nelson D L. Soluble interleukin 2 B, Yarchoan $R$, Nelson $D$ L. Soluble interleukin 2 receptors are released from activated hum

13 Wolf R E, Brelsford W G. Soluble interleukin-2 receptors in systemic lupus erythematosus. Arthritis Rheum 1988; 31: 729-35.

14 Takano Y, Kanai Y, Hashimoto H, Okumura K, Hirose S. Soluble interleukin 2 receptors in patients with polymyositis/dermatomyositis. Ann Rheum Dis 1992; 51 $781-2$.

15 Keystone E C, Snow K M, Bombardier C, Chang C, Nelson D L, Rubin L A. Elevated soluble interleukin-2 recepto levels in the sera and synovial fluids of patients with Rheumatoid arthritis. Arthritis Rheum 1989; 31: 844-9.

16 Campen D H, Horwitz D A, Quismorio F P, Ehresman G R, Martin W J. Serum levels of interleukin-2 recepto and activity of rheumatic diseases characterized by immune system activation. Arthritis Rheum 1988; 31: 1358-64.

17 Rubin L A, Kurman C C, Fritz M E, Yarchoan R, Nelson $D$ L. Identification and characterization of a released form of the interleukin-2 receptor. In: J J Oppenheim, ed. The role of leukocytes in host defense. New York: Alan R Liss, role of
1985. 
18 Schmitt W H, Heesen C, Csernok E, Rautmann A, Gross W L. Elevated serum levels of soluble interleukin-2 L. Elevated serum levels of soluble interleukin-2 Association with disease activity. Arthritis Rheum 1992; 35: 1088-95.

19 Symons J A, Wood N C, Di Giovine F S, Duff G W. Soluble IL-2 receptor in rheumatoid arthritis. Correlation with disease activity, IL-1 and IL-2 Inhibition. F Immunol 1988; 141: 2612-18

20 Wood N C, Symons J A, Duff G W. Serum Interleukin2-receptor in rheumatoid arthritis: A prognostic indicator of disease activity? 7 Autoimmunity 1988; 1 : 353-61.

21 Reed J C, Abidi A H, Alpers J D, Hoover R G, Robb R J, Nowell P C. Effect of cyclosporin A and dexamethasone on interleukin 2 receptor gene expression. $f$ Immunol 1986; 137: $150-4$

22 Sfikakis P P, Souliotis V L, Panayiotidis P P. Suppression of interleukin-2 and interleukin-2 receptor biosynthesis by gold compounds in vitro activated human peripheral bolod mononuclear cells. Arthritis Rheum 1993; 36: 208-12.

23 Arnett F C, Edworthy S M, Bloch D A, et al. The American Rheumatism Association 1987 revised criteria for the classification of rheumatoid arthritis. Arthritis Rheum 1988; 31: 315-24

24 Lansbury J. Methods for evaluating rheumatoid arthritis, arthritis and allied conditions. In: $\mathrm{J}$ L Hollander, ed. Philadelphia: Lea and Febiger, 1966.

25 Pinals R S, Masi A T, Larsen R A. Subcommittee for Criteria of Remission in Rheumatoid Arthritis of the
American Rheumatism Association Diagnostic and Thereapeutic Criteria Commitee: preliminary criteria for Thereapeutic Criteria Commitee: preliminary criteria for
clinical remission in rheumatoid arthritis. Arthritis Rheum 1981; 24: 1308-15.

26 Sox $H C$, Liang $M H$. The erythrocyte sedimentation rate. Guidelines for rational use. Annals of Internal Medicin 1986; 104: 515-23.

27 Blaese R M, Grayson J, Steinberg A D. Increased immunoglobulin-secreting cells in the blood of patients with active systemic lupus erythematosus. Am 7 Med 1980; 69; 345-50.

28 Thomas $R$, Mcilraith M, Davis L S, Lipsky P E Rheumatoid synovium is enriched in CD45RB ${ }^{\text {dim }}$ mature Rheumatoid synovium is enriched in CD45R memory T cells that are potent helpers for B cell differ
tiation. Arthritis and Rheumatism 1992; 35: 1455-65.

29 Wagner D K, Wong H L, Gately M K, Nelson D L. Cellula source of soluble interleukin 2 receptors in serum of mice after recombinant interleukin 2 administration. Cytokine 1990; 2: 337-43.

30 Wood N C, Symons T A, Duff G U. Serum interleukin2-receptor in rheumatoid arthritis; A prognostic indicator of disease activity? $¥$ Autoimmunity 1988; $1: 353-61$.

31 Fox R I, Fong Sherman, Sabharwal N, Carstens S A, Kung P C, Vaughan J H. Synovial fluid lymphocytes differ from peripheral blood lymphocytes in patients with rheumatoid arthritis. $\mathcal{F}$ Immunol 1982; 128: $351-4$.

32 Symons J A, McCulloch J F, Wood N C, Duff G W. Soluble CD4 in patients with rheumatoid arthritis and osteoarthritis. Clin Immunol Immunopathol 1991; 60: 72-82. 